Paper 199

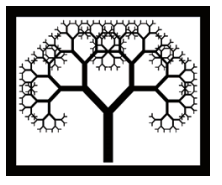

CCivil-Comp Press, 2007

Proceedings of the Eleventh International Conference

on Civil, Structural and Environmental

Engineering Computing,

B.H.V. Topping (Editor),

Civil-Comp Press, Stirlingshire, Scotland

\title{
Influence of the Location of Resistant Cores on the Seismic Response of a Reinforced Concrete Three-Dimensional Frame Equipped with HDRB Base Isolation Devices
}

\author{
M.T. Braz César ${ }^{1}$ and R.C. Barros ${ }^{2}$ \\ ${ }^{1}$ Polytechnic Institute of Bragança, Portugal \\ ${ }^{2}$ Department of Civil Engineering, University of Porto, Portugal
}

\begin{abstract}
The present work addresses the structural behaviour of three-dimensional reinforced concrete buildings with concrete cores of resistant walls and seismic isolation. In this study a single asymmetric concrete core was placed in a 10 floor 3D building and then a set of numerical analyses were made for several geometric arrangements without and with High-Damping Rubber Bearings (HDRB). This base isolation system is used in order to reduce the structural seismic response and its associated damage. In order to evaluate the importance of the basic location of these structural elements, a parametric study was carried out changing the in-plan core location associated with symmetrical and asymmetrical structural distribution of the in-plan stiff core. The buildings were modelled using the commercial package SAP-2000 and the seismic analyses were carried out in accordance with the new European Code for seismic analysis and design: Eurocode 8 (EC8); the national annex was used to define the Portuguese elastic spectra.
\end{abstract}

Keywords: seismic isolation, HDRB, seismic behaviour, asymmetric 3D frames, parametric studies, earthquake design.

\section{Introduction}

A few years ago a simplified dynamic analysis was the sufficient answer for the engineering needs related with seismic design. Indeed, the limited computer hardware and the processing time needed for realistic analysis conditioned the application of more complex algorithms. This classical limitation still remains in nowadays structural design, namely for small projects with reduced economic and social importance for which simple software with linear elastic algorithms are often used and design spectrum analysis is carried out for seismic design. 
Architectural mistakes, often related with mismatched structural conceptions, also contribute to a non-ideal structural behaviour and performance but in this case a few design reflections are sufficient to overcome this issue as proposed in new codes regulations for plan, elevation, mass and stiffness asymmetry limitations.

The characterization of the buildings seismic response, and its relation with different structural configurations, is a basic requirement for the definition of structural conception associated with zones of moderate to high seismic risk. To achieve acceptable lateral stiffness and resistance in both in-plan directions, the buildings must have adequate torsion stiffness in order to limit distortion effects along the height. A non-uniform distribution of efforts in the resisting vertical structural elements is expected, and this requires a performance and behaviour analysis of distinct stiff core locations to ascertain lateral stiffness limitations.

The basic building vibration shapes must be preferentially translation mode shapes, preventing the appearance of twist modes associated with rotation modes. A simple way to evaluate the importance of these modes in the structural response consists in evaluating the directional effective modal masses, normally express in percentage of the total mass of the structure.

In the real construction world current tall buildings have a framed structure stiffened with panels and shear walls, to reduce the lateral displacements and practically ensure a un-sway mode for static design, and to reduce torsion effects connected with the dynamic and seismic design. A simple way to achieve this is obtained by introducing a concrete core around the stairs and elevators case.

Indeed this is a common procedure in low seismic regions and so far a $2 \mathrm{D}$ structural analysis can be carried out to evaluate the dynamic structural response and to guarantee sufficient lateral resistance and stiffness for the applied lateral forces, like seismic or wind actions. A 3D structural analysis, more complex by nature, allows identifying torsion effects that a $2 \mathrm{D}$ analysis cannot handle. So it is intended to study structural configurations of a 3D building with a concrete core, describing its dynamic and seismic response. At this stage a simple core becomes a more obvious choice for analysis, since distinct in-plan core locations most of times may cause distinct significant torsion effects.

To achieve this, a structural configuration for a base-frame was defined without the concrete core. This structural configuration is a 10-floor high building with concrete columns and beams and rigid diaphragm planes defined by a $0,20 \mathrm{~m}$ thickness. Different structural configurations were obtained from the initial base configuration in which (stairs and elevators case) in-plan core location is modified in order to vary stiffness asymmetry. This resisting core is placed to create additional resistance that before and during the occurrence of an earthquake guarantee the structural stability and the capacity necessary to dissipate the seismic energy.

If some additional energy dissipation is needed a dissipation system can be added to the structural scheme, to reduce damage and repair costs. Another way to reduce seismic energy consequences across the structure is to change the structural stiffness, by shifting the main period range through an isolation system. At this stage one of the most economical systems is based on passive base isolation devices, namely rubber bearings (of High-Damping Rubber Bearings HDRB type). 
So, the final purpose of this work is to study the influence of a HDRB system into the overall structural behavior with a resisting core, and also to relate it with the inplan core location. These analyses for the present 3D reinforced concrete building base-frame are done in the sequel of an earlier study (Barros and Cesar [1], [2]) on the seismic behaviour of an asymmetric 3D steel frame with base isolation devices.

\section{Structural Analyses for a Parametric Study}

\subsection{Structural layout}

To carry out the study about the seismic performance of a structure with a concrete core without and with base isolators, a 10 floor reinforced concrete building with 3 meters inter storey height was analysed. The structure has three bays with 4 meters each in one direction and five bays with 5 meters each in the perpendicular direction as shown in Figure 1. It has a modularity of one parametric study already done by the authors for the carrying capacity of 3D metallic frames (Cesar and Barros [3]).

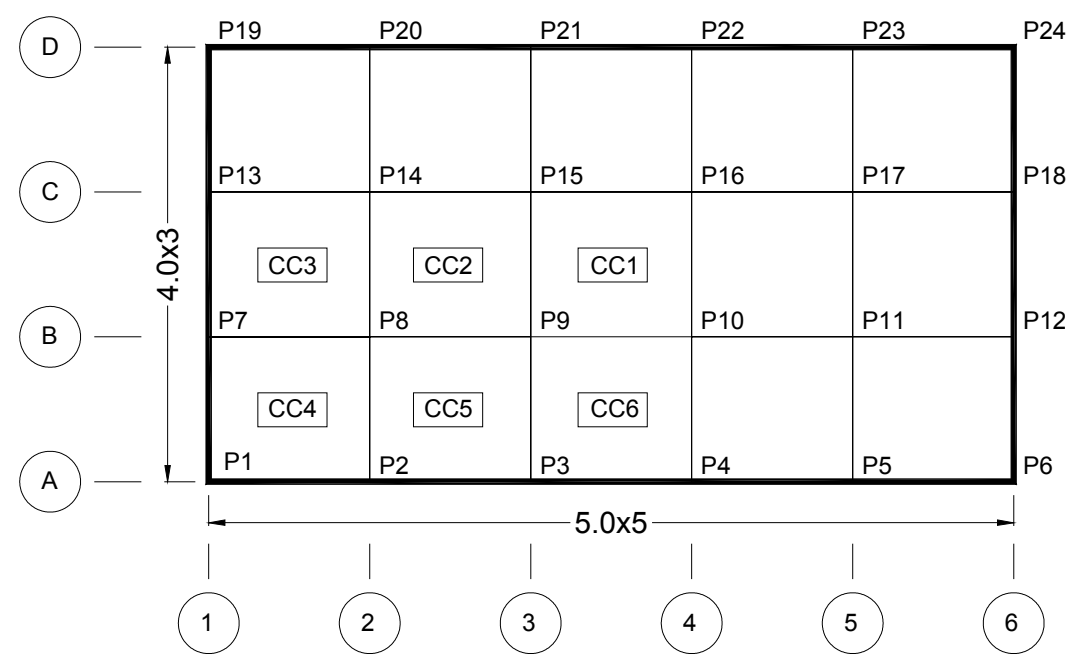

Figure 1: Plant view of the 10 floor regular building

The sectional dimensions of the resisting elements were designed considering a $\mathrm{C} 20 / 25$ concrete grade and a $348 \mathrm{MPa}$ yield stress steel grade, in accordance to Eurocode 2 (CEN-EC2 [4]). To quantify the structural actions the building was considered located at Faro, which is one of the highest seismic activity zones in southern Portugal. Beams have a constant cross section of $0,30 \times 0,40 \mathrm{~m}^{2}$ and columns have the dimensions indicated in Table 1. For the planar stiffening elements the following thickness have been adopted: $0,20 \mathrm{~m}$ for the concrete core and $0,15 \mathrm{~m}$ for the concrete slab.

Initially the analysed structure presents regularity in both plan and elevation (without concrete cores), so that the first parametric variation of the structural system is associated with the location of the further added concrete core (CC i ). Six such concrete core locations were studied, as indicated in Figure 1, starting at the stairs and elevator case CC1 and ending at the case CC6. 


\begin{tabular}{|c|c|c|c|c|}
\hline Floor & $\begin{aligned} \mathbf{P 1} & =\mathbf{P 6} \\
\mathbf{P 1 9} & =\mathbf{P} 24\end{aligned}$ & $\begin{array}{c}\mathrm{P2}=\mathbf{P} 3=\mathbf{P 4} \\
\mathrm{P5}=\mathbf{P 2 0}=\mathbf{P 2 1} \\
\mathbf{P 2 2}=\mathbf{P 2 3}\end{array}$ & $\begin{array}{c}\mathrm{P} 7=\mathrm{P} 13 \\
\mathrm{P} 12=\mathrm{P} 18\end{array}$ & $\begin{array}{c}\mathrm{P} 8=\mathrm{P} 9=\mathrm{P} 10 \\
\mathrm{P} 11=\mathrm{P} 14=\mathrm{P} 15 \\
\mathrm{P} 16=\mathrm{P} 17\end{array}$ \\
\hline 9,10 & $0.3 \times 0.3$ & $0.3 \times 0.3$ & $0.3 \times 0.3$ & $0.3 \times 0.3$ \\
\hline 8 & $0.4 \times 0.3$ & $0.3 \times 0.3$ & $0.3 \times 0.3$ & $0.3 \times 0.3$ \\
\hline 7 & $0.4 \times 0.3$ & $0.4 \times 0.3$ & $0.3 \times 0.3$ & $0.4 \times 0.4$ \\
\hline 6 & $0.5 \times 0.3$ & $0.4 \times 0.3$ & $0.3 \times 0.4$ & $0.4 \times 0.4$ \\
\hline 5 & $0.5 \times 0.3$ & $0.5 \times 0.3$ & $0.3 \times 0.4$ & $0.4 \times 0.4$ \\
\hline 4 & $0.6 \times 0.3$ & $0.5 \times 0.3$ & $0.3 \times 0.4$ & $0.4 \times 0.4$ \\
\hline $1,2,3$ & $0.6 \times 0.3$ & $0.6 \times 0.3$ & $0.3 \times 0.5$ & $0.5 \times 0.5$ \\
\hline
\end{tabular}

Table 1: Columns cross sectional dimensions

As shown in Figure 2 the parametric variation is related with a translation of the core location, generating an in-plan stiffness asymmetric structure. The first configuration (CC1) locates the resisting concrete core in the central zone of the building, while the remaining variations correspond to the displacement of that core to more eccentric positions. A vertical opening in the concrete core was considered $(\mathrm{L}=2.0 \mathrm{~m}$ and $\mathrm{H}=3.0 \mathrm{~m})$ related to door openings. Although this opening is realistic, it leads to a lack of absolute structural symmetry of the initial configuration of the resisting structural system $(\mathrm{CC} 1)$ along the smallest in-plan dimension.

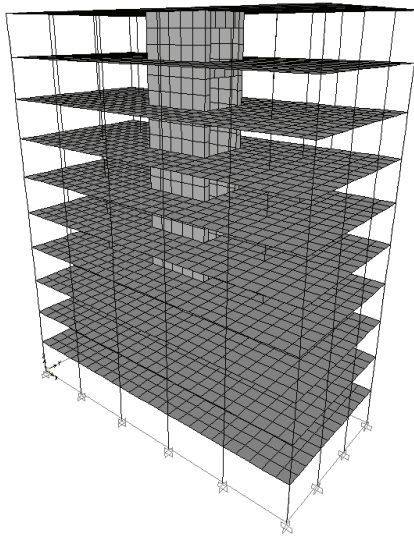

(a)

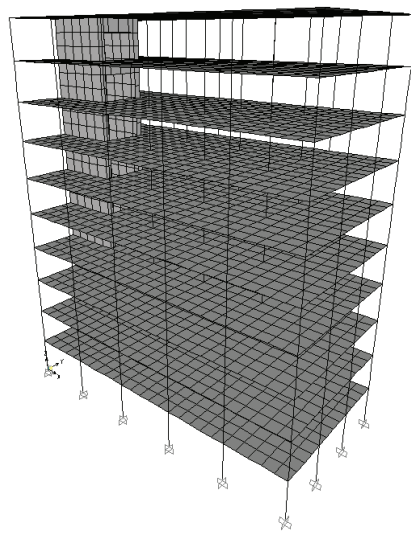

(b)

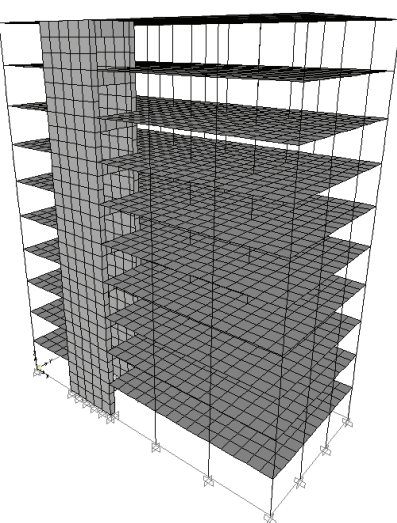

(c)

Figure 2: Perspective view for several core locations: a) $\mathrm{CC}$; b) CC3; c) CC5

\subsection{Structural model and loading}

The structural models were elaborated with SAP 2000 version 10 software package [5]. Columns and beams were modelled as linear finite elements while core walls and slabs were modelled as shell finite elements. Fixed restraint columns were used to simulate the foundation connection and a rigid diaphragm constraint was used to model the slab degrees of freedom, due to the high in-plan stiffness. Finally, to ensure a correct column torsion behavior, a $75 \%$ stiffness reduction was considered. 
The followed model strategy ensures that the structural model adequately reproduces the distribution of mass and stiffness of the real structure, to acquire more realistic frequencies, mode shapes and representative forces of inertia of the analysed structures (SAP 2000 [6]). Although foundation ground deformability can also be important in this type of structures, such effect was not considered herein.

The structure was predesigned according to Eurocode 2 (CEN-EC2 [4]) and Eurocode 8 (CEN-EC8 [7]) and National codes when the Eurocodes could not be applied. Permanent actions include self-weight $\left(1,3 \mathrm{kN} / \mathrm{m}^{2}\right)$ and inner constructive walls $\left(1,2 \mathrm{kN} / \mathrm{m}^{2}\right)$ at every floor. Exterior walls self-weight was also considered as a linear load $(8,0 \mathrm{kN} / \mathrm{m})$ acting along the building periphery. Live load on the floor caused by human activity in the residential building was $2,0 \mathrm{kN} / \mathrm{m}^{2}$ at the intermediate floors and $0,4 \mathrm{kN} / \mathrm{m}^{2}$ at the roof. Structural mass was calculated in accordance with the rules proposed in Eurocode 8 (CEN-EC8 [7]).

In this study were used the earthquake response spectra presented in the National Annex (NA) - in the last stages of preparation phase, prior to constitute an official technical national amendment - of the EC8 [7]. In accordance with this design code, the seismic action can be defined either in terms of an elastic response spectrum (Figure 3) or as real or artificial compatible accelerogram. Two types of earthquakes were considered - Type 1 earthquake $\left(\mathrm{PGA}=2,00 \mathrm{~m} / \mathrm{s}^{2}, \mathrm{~TB}=0,10 \mathrm{~s}, \mathrm{TC}=0,60 \mathrm{~s}\right.$ and $\mathrm{TD}=2,00 \mathrm{~s})$ and Type 2 earthquake $\left(\mathrm{PGA}=1,70 \mathrm{~m} / \mathrm{s}^{2}, \mathrm{~TB}=0,10 \mathrm{~s}, \mathrm{TC}=0,25 \mathrm{~s}\right.$ and $\mathrm{TD}=2,00 \mathrm{~s}$ ) - related with the building location and a soil-type 1 (hard soil). Also the seismic behavioural coefficient equals unity for a $5 \%$ damping factor. Through this data is concluded that Type 2 earthquake is the more hazardous.

Such design spectra were introduced in SAP 2000 software package [5], for determining structural responses under the most unfavourable actions combination.

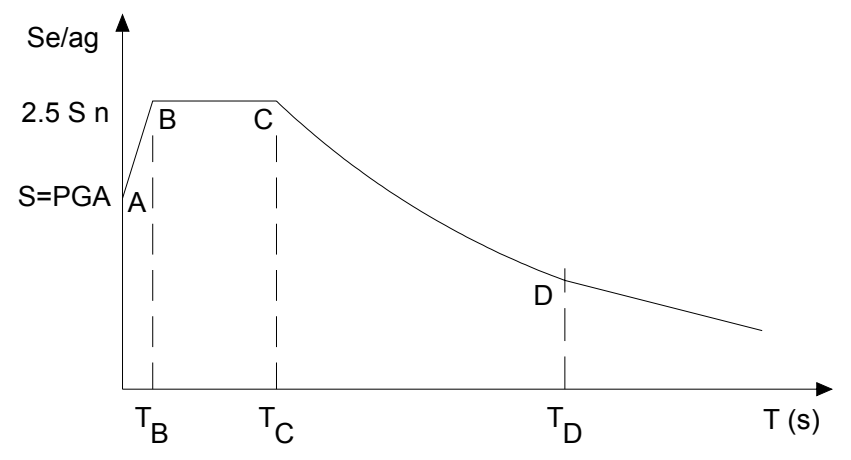

EC8 - National Annex (2007)

\begin{tabular}{|c|c|c|}
\cline { 2 - 3 } \multicolumn{1}{c|}{} & Type 1 & Type 2 \\
\hline $\mathrm{S}=$ PGA & 2.00 & 1.70 \\
\hline TB & 0.10 & 0.10 \\
\hline TC & 0.60 & 0.25 \\
\hline TD & 2.00 & 2.00 \\
\hline \multicolumn{2}{|c}{$\mathrm{S}\left(\mathrm{m} / \mathrm{s}^{2}\right) ; \mathrm{T}(\mathrm{sec})$}
\end{tabular}

Figure 3: Elastic response spectrum according to EC8 and NA (Portugal)

As the seismic response of the concrete structures considered herein is eminently non-linear, the use of the design spectrum instead of the elastic spectrum prevents the execution of non-linear analyses and takes into account the energy dissipation capacity of the structure. However, in this work, it was opted to use the elastic spectrum, making unnecessary the use of the behaviour coefficient. So, the results obtained through the linear analysis are higher than the values needed for seismic design. 
This aspect is not significant in this work, since it is not intended to obtain the design efforts but essentially to compare the structural responses of the building associated with distinct core locations. The related accidental torsion effect is contemplated through the consideration of a prescribed eccentricity equal to $5 \%$ of the corresponding dimension in-plan, in accordance with the prescribed recommendations in Eurocode 8 (CEN-EC8 [7]).

\subsection{Dynamic and seismic response of the non-isolated structure}

In this section a dynamic characterization of the 3D structure under study is presented, for different structural configurations of the concrete core (CC1 to $\mathrm{CC} 6)$, in terms of: fundamental frequencies, mode shapes and directional effective modal mass coefficients.

The first mode shape for each configuration is graphically illustrated in Figure 4, which clearly indicates that the controlling behaviour has a torsion mode character. A low fundamental frequency (less than $1.0 \mathrm{~Hz}$ ) is obtained for all structural core configurations, and this fact is associated with a high structural flexibility.

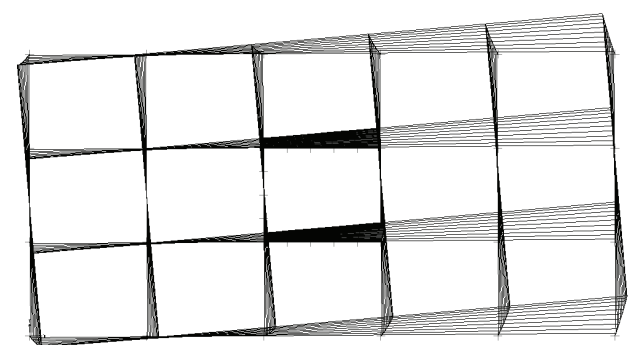

$\mathrm{CC} 1: \mathrm{f}_{1}=0.79 \mathrm{~Hz}$

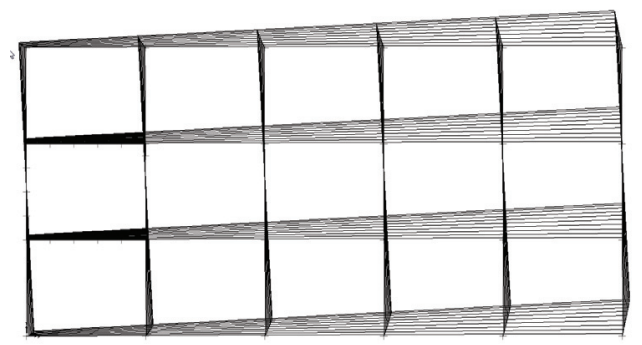

$\mathrm{CC} 3: \mathrm{f}_{1}=0.60 \mathrm{~Hz}$

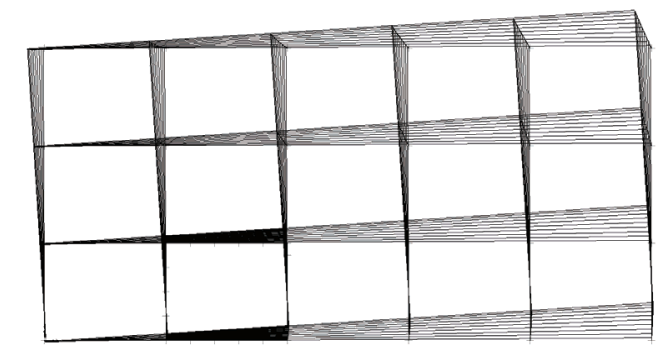

CC5: $f_{1}=0.64 \mathrm{~Hz}$

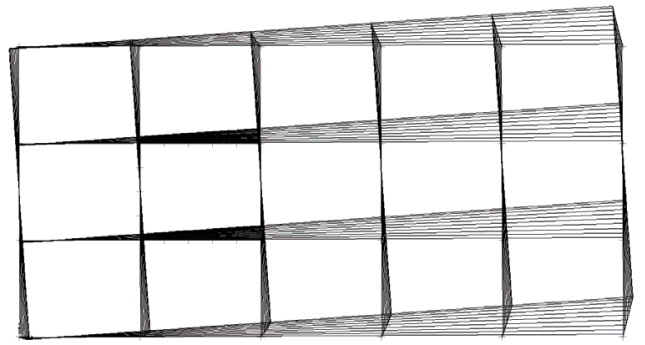

$\mathrm{CC} 2: \mathrm{f}_{1}=0.64 \mathrm{~Hz}$

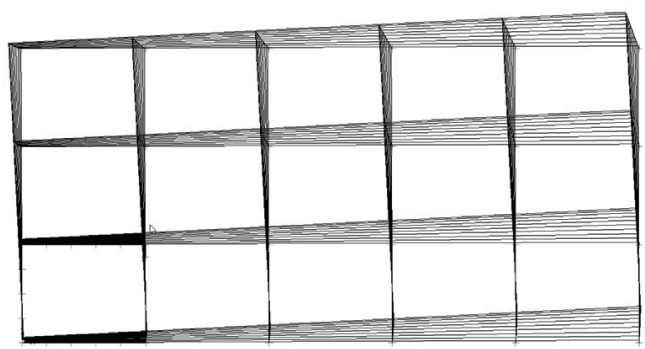

$\mathrm{CC} 4: \mathrm{f}_{1}=0.59 \mathrm{~Hz}$

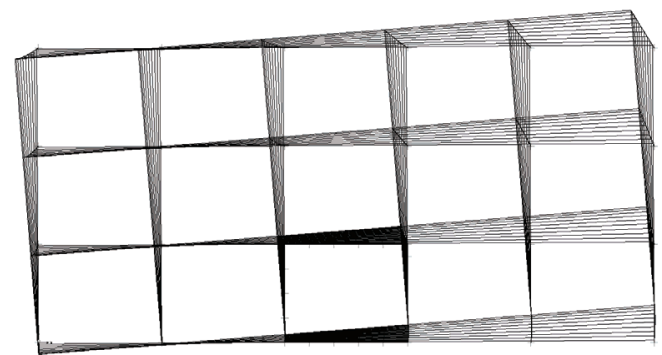

CC6: $\mathrm{f}_{1}=0.71 \mathrm{~Hz}$

Figure 4: Fundamental frequencies and mode shapes for each building 
Table 2 shows the natural frequencies and mode shapes for six modal configurations. Natural frequencies associated with global torsion mode decrease gradually with the core translation to a peripheral zone and this torsion mode shape is significant for all parametric variations. However, the data contained in Table 2 does not give information about the relative importance of each mode in seismic response. This evaluation can be achieved through modal participating mass ratios associated to each independent degree of freedom.

\begin{tabular}{|c|c|c|c|c|c|c|c|c|c|c|c|c|}
\hline \multirow{2}{*}{ Mode } & \multicolumn{2}{|c|}{ CC1 } & \multicolumn{2}{c|}{ CC2 } & \multicolumn{2}{c|}{ CC3 } & \multicolumn{2}{c|}{ CC4 } & \multicolumn{2}{c|}{ CC5 } & \multicolumn{2}{c|}{ CC6 } \\
\cline { 2 - 13 } & $\begin{array}{c}\text { Freq } \\
(\mathbf{H z})\end{array}$ & mode & $\begin{array}{c}\text { Freq } \\
\mathbf{( H z )}\end{array}$ & mode & $\begin{array}{c}\text { Freq } \\
\mathbf{( H z )}\end{array}$ & mode & $\begin{array}{c}\text { Freq } \\
\mathbf{( H z )}\end{array}$ & mode & $\begin{array}{c}\text { Freq } \\
(\mathbf{H z})\end{array}$ & mode & $\begin{array}{c}\text { Freq } \\
(\mathbf{H z})\end{array}$ & mode \\
\hline 1 & 0.79 & $\mathrm{Rz}$ & 0.64 & $\mathrm{Rz}$ & 0.60 & $\mathrm{Rz}$ & 0.59 & $\mathrm{Rz}$ & 0.64 & $\mathrm{R}$ & 0.71 & $\mathrm{Rz}$ \\
\hline 2 & 1.07 & $\mathrm{Ty}$ & 1.05 & $\mathrm{Tx}$ & 1.02 & $\mathrm{Tx}$ & 1.00 & $\mathrm{Txy}$ & 1.01 & $\mathrm{Txy}$ & 0.94 & $\mathrm{Txy}$ \\
\hline 3 & 1.10 & $\mathrm{Tx}$ & 1.25 & $\mathrm{Ty}$ & 1.51 & $\mathrm{Rz}$ & 1.49 & $\mathrm{Rz}$ & 1.31 & $\mathrm{Rz}$ & 1.17 & $\mathrm{Rz}$ \\
\hline 4 & 2.34 & $\mathrm{Rz}$ & 1.83 & $\mathrm{Rz}$ & 1.74 & $\mathrm{Rz}$ & 1.73 & $\mathrm{Rz}$ & 1.88 & $\mathrm{Rz}$ & 2.11 & $\mathrm{Rz}$ \\
\hline 5 & 3.77 & $\mathrm{Rz}$ & 3.18 & $\mathrm{Rz}$ & 2.95 & $\mathrm{Rz}$ & 2.91 & $\mathrm{Rz}$ & 3.23 & $\mathrm{Rz}$ & 3.43 & $\mathrm{Rz}$ \\
\hline 6 & 4.11 & $\mathrm{Rz}$ & 4.21 & $\mathrm{Tx}$ & 4.23 & $\mathrm{Rz}$ & 4.10 & $\mathrm{Rz}$ & 3.89 & $\mathrm{Rz}$ & 3.67 & $\mathrm{Rz}$ \\
\hline
\end{tabular}

Tx: Translation $\mathrm{x}-\mathrm{x}$; Ty: Translation y-y; Txy: Translation $\mathrm{x}-\mathrm{x}$ and $\mathrm{y}-\mathrm{y} ;$ Rz: Rotation $\mathrm{z}-\mathrm{z}$ (or torsion)

Table 2: Natural frequencies and mode shapes

To understand the buildings dynamic behavior, Table 3 shows the values of the modal participation mass ratios for each direction (translations $\mathrm{x}-\mathrm{x}$ and $\mathrm{y}-\mathrm{y}$, and rotation around the vertical axis $\mathrm{z}-\mathrm{z}$ ). In Table 3 , the shaded cells are associated with the maximum value of the modal participation mass ratios. Generally, as the core is dislocated to a peripheral position, the importance of the torsion mode increases; this is undesirable on a dynamic point of view. On the other hand, in all the situations the first mode shape constitutes the biggest contribution in a torsion response, which is contrary to what is desirable under the spirit of the EC8 and under the principles of structural conception of buildings in seismic zones.

\begin{tabular}{|c|c|c|c|c|c|c|c|c|c|c|c|c|c|c|c|c|c|c|}
\hline \multirow{2}{*}{ Mode } & \multicolumn{3}{|c|}{ CC1 (\%) } & \multicolumn{3}{|c|}{ CC2 (\%) } & \multicolumn{3}{|c|}{ CC3 (\%) } & \multicolumn{3}{|c|}{ CC4 (\%) } & \multicolumn{3}{|c|}{ CC5 (\%) } & \multicolumn{3}{|c|}{ CC6 (\%) } \\
\hline & $\mathbf{x x}$ & yy & $\theta \mathrm{z}$ & $\mathrm{xx}$ & yy & $\theta \mathrm{z}$ & $\mathrm{xx}$ & yy & $\theta \mathrm{z}$ & $\mathbf{X x}$ & yy & $\theta \mathrm{z}$ & $\mathrm{xx}$ & yy & $\theta z$ & $\mathbf{x x}$ & yy & $\theta \mathrm{z}$ \\
\hline 1 & 0 & 27 & 59 & 0 & 46 & 65 & 0 & 58 & 65 & 4 & 55 & 74 & 7 & 43 & 76 & 16 & 19 & 67 \\
\hline 2 & 0 & 41 & 4 & 66 & 0 & 9 & 66 & 0 & 9 & 61 & 6 & 2 & 50 & 16 & 0 & 17 & 47 & 6 \\
\hline 3 & 66 & 0 & 9 & 0 & 23 & 0 & 0 & 7 & 5 & 1 & 5 & 5 & 9 & 10 & 0 & 34 & 3 & 0 \\
\hline 4 & 0 & 4 & 9 & 0 & 11 & 11 & 0 & 18 & 7 & 2 & 17 & 8 & 2 & 10 & 12 & 4 & 3 & 11 \\
\hline 5 & 0 & 11 & 2 & 0 & 2 & 4 & 0 & 3 & 4 & 0 & 3 & 5 & 1 & 1 & 4 & 2 & 12 & 2 \\
\hline 6 & 0 & 6 & 6 & 20 & 0 & 3 & 0 & 2 & 2 & 17 & 3 & 0 & 11 & 8 & 0 & 0 & 5 & 6 \\
\hline 7 & 21 & 0 & 3 & 0 & 11 & 1 & 21 & 0 & 3 & 0 & 1 & 2 & 1 & 1 & 2 & 15 & 1 & 1 \\
\hline 8 & 0 & 0 & 1 & 0 & 0 & 2 & 0 & 0 & 1 & 0 & 0 & 1 & 7 & 3 & 0 & 0 & 0 & 0 \\
\hline 9 & 0 & 0 & 0 & 0 & 1 & 1 & 0 & 7 & 0 & 2 & 5 & 0 & 0 & 1 & 1 & 0 & 0 & 0 \\
\hline 10 & $\underline{0}$ & 0 & 0 & 0 & 0 & 1 & 0 & 0 & 0 & 0 & 0 & 0 & 0 & 0 & 0 & 0 & 0 & 0 \\
\hline 11 & 0 & 0 & 0 & 0 & 0 & 0 & 0 & 0 & 0 & 0 & 0 & 0 & 0 & 0 & 0 & 0 & 0 & 0 \\
\hline 12 & 0 & 0 & 0 & 0 & 0 & 0 & 0 & 0 & 0 & 0 & 0 & 0 & 0 & 0 & 0 & 0 & 0 & 1 \\
\hline
\end{tabular}

\begin{tabular}{|l|l|l|l|l|l|l|l|l|l|l|l|l|l|l|l|l|l|l|}
$\boldsymbol{\Sigma}$ & $\mathbf{8 7}$ & $\mathbf{8 9}$ & $\mathbf{9 3}$ & $\mathbf{8 6}$ & $\mathbf{9 4}$ & $\mathbf{9 7}$ & $\mathbf{8 7}$ & $\mathbf{9 5}$ & $\mathbf{9 6}$ & $\mathbf{8 7}$ & $\mathbf{9 5}$ & $\mathbf{9 7}$ & $\mathbf{8 8}$ & $\mathbf{9 3}$ & $\mathbf{9 5}$ & $\mathbf{8 8}$ & $\mathbf{9 0}$ & $\mathbf{9 4}$ \\
\hline
\end{tabular}

Table 3: Modal participation mass ratios (\%) 
The last line of Table 3 represents the sum of the modal participation mass ratios associated with the first twelve mode shapes. In accordance with EC8, the evaluation of the seismic effect (for each direction) by the modal superposition method must involve a minimum number of modes, such that the sum of its effective contributing masses is not inferior to $90 \%$ of the total mass of the structure. It is verified that the seismic analysis will have more than twelve mode shapes. In this work the seismic effect has been calculated through the complete quadratic combination of the modal results in the first fifteen mode shapes.

Finally, a simplified spectral seismic analysis was carried out for the most unfavorable seismic actions (Type 2 with $\mathrm{PGA}=0.20 \mathrm{~g}$ ) acting in $\mathrm{y}$-y direction.

The structural seismic response of each building can be compared on the basis of floor displacements along the height and basal shear, that constitute possible global measures of the importance of seismic actions. The relative horizontal floor displacements, at reference column P6 (labelled in Figure 1) and at the concrete core, are represented in Figures 5 and 6 respectively for each $\mathrm{x}-\mathrm{x}$ and $\mathrm{y}-\mathrm{y}$ directions.

The absence of significant horizontal core translation along $\mathrm{x}-\mathrm{x}$ direction (for buildings with concrete core configurations $\mathrm{CC} 1, \mathrm{CC} 2$ and $\mathrm{CC} 3$ ) indicates an increase of the floors rotation around the stiffness centre (as shown in Figure 4) and therefore an increase of column P6 horizontal displacement along y-y direction (as shown in Figure 6-a). Therefore the insignificant core displacements in the horizontal $\mathrm{x}-\mathrm{x}$ direction of the three first core configurations (CC1, CC2 and CC3) indicate that the seismic response is governed by the effect of the translation in the other $y-y$ direction with torsion around the core. However, for the remaining concrete core configurations (CC4, CC5 and CC6), the core displacements in $\mathrm{x}-\mathrm{x}$ direction become significant, reaching almost half of the value observed for the core displacements in $\mathrm{y}-\mathrm{y}$ direction. Thus, it is expected that the total shear in $\mathrm{x}-\mathrm{x}$ direction for this set to be clearly superior to the total shear in $\mathrm{x}-\mathrm{x}$ direction for the first set of buildings.

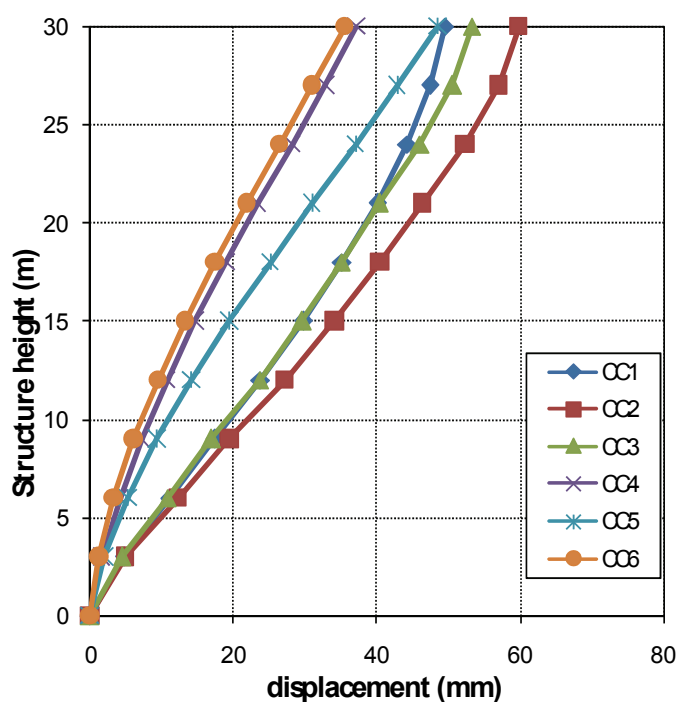

(a)

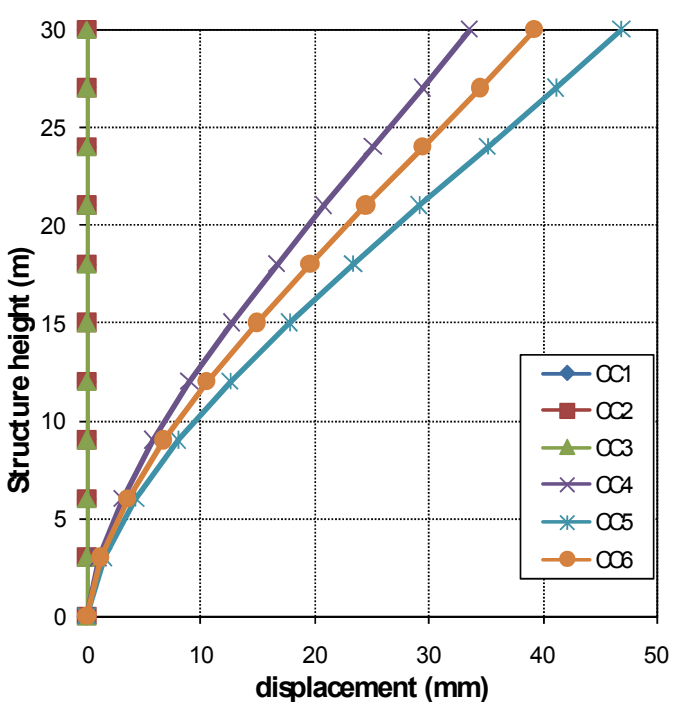

(b)

Figure 5: Horizontal $x-x$ displacements: a) P6 column; b) concrete core 


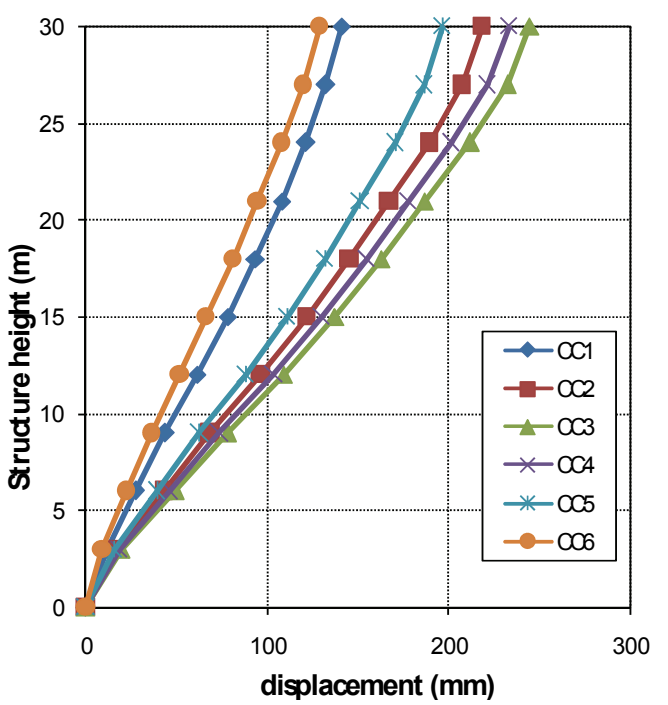

(a)

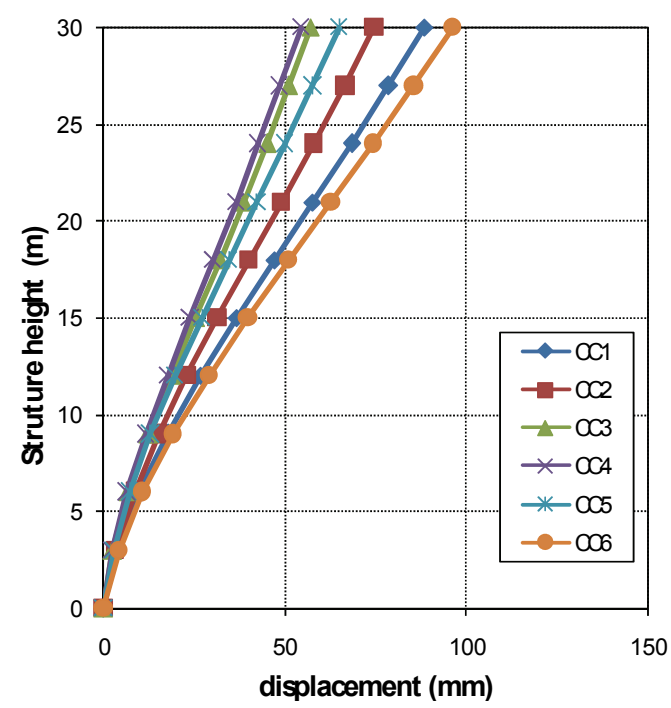

(b)

Figure 6: Horizontal y-y displacements: a) P6 column; b) concrete core

Comparing the horizontal displacements in $y-y$ direction at core and at column $\mathrm{P} 6$, for concrete core configurations $\mathrm{CC} 2$ to $\mathrm{CC} 5$, it is verified that the column displacements are significantly higher (double to triple) than the core displacements; for core configurations $\mathrm{CC} 1$ and $\mathrm{CC} 6$, the horizontal displacements in $\mathrm{y}-\mathrm{y}$ direction are of the same order of magnitude. Nevertheless, both results indicate the high importance of torsion in the seismic responses of these non-isolated configurations.

\subsection{Dynamic and seismic response of the base isolated structure}

The fundamental feature of a base isolation system is to alter and adjust the response of the structure so that the ground can move without transmitting that motion to the building, therefore separating dynamically the structure from the ground.

The global structural stiffness influences significantly the movement that the ground transmits to the structure and consequently the seismic force magnitude that the structure has to resist. For any major earthquake there is a range of frequencies (or periods) that amplifies the structure acceleration beyond the maximum ground acceleration, while the peak ground displacement verifies the structural drift limitation.

A typical elastic response spectrum (Figure 7) shows earthquake accelerations with dominant periods between $0.10 \mathrm{sec}$ to $1 \mathrm{sec}$, with maximum magnitude at periods of about $0.20 \mathrm{sec}$ to $0.60 \mathrm{sec}$. If the structural system has fundamental periods that lie into this interval then seismic actions can produce serious damage due to resonance effects.

The base isolation system increases the structural flexibility and consequently the main period to a more secure range in which resonance effects are significantly lower (and often irrelevant). Therefore base isolation constitutes an efficient measure for vibration control, through deflecting the structural response for higher periods. The period shift effect shown in Figure 7, constitutes a type of pseudo-filter. 


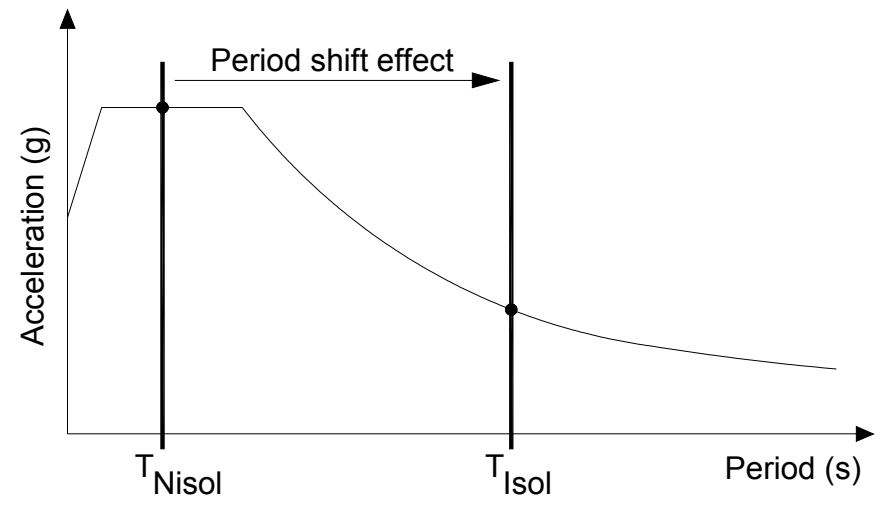

Figure 7: Elastic response spectrum and "shift" effect due to base isolation

Several design methodologies can be used to design base isolation systems, for initially non-isolated structures. Basically the vertical and horizontal rigidities of the group of base isolators are designed, in function of the resistant capacities required by the design earthquake, for a design period or "target" period of $\mathrm{T}_{\mathrm{s}}=2 \sec$ (that corresponds to the mentioned "shift" effect). For pre-design of an isolated structure, according to the elastic response spectrum, the structure must have a fundamental period between 1,5 sec and $3 \mathrm{sec}$; this target period must be twice the rigid based structure fundamental period (Skinner et al. [8]).

The elastomeric isolators, applied at the bottom of each column, are designed according to the following procedure:

1. Horizontal and vertical stiffness $\left(\mathrm{K}_{\mathrm{h}}\right.$ and $\left.\mathrm{K}_{\mathrm{v}}\right)$

Horizontal stiffness $\left(\mathrm{K}_{\mathrm{h}}\right)$ and vertical stiffness $\left(\mathrm{K}_{\mathrm{v}}\right)$ are given by the following equations:

$$
\begin{aligned}
& K_{h}=\frac{G \cdot A}{t} \\
& K_{v}=\frac{E \cdot A}{t}
\end{aligned}
$$

where $\mathrm{G}$ is the shear modulus, $\mathrm{E}$ is the compression modulus, $\mathrm{A}$ is the cross section area and $t$ is the rubber thickness.

Shear modulus is in the range of $0.5 \mathrm{MPa}<\mathrm{G}<2.5 \mathrm{MPa}$, and the compression modulus can be obtained by the following equation (Naeim and Kelly [9]):

$$
E=\left(\frac{1}{6 \cdot G \cdot S^{2}}+\frac{1}{K}\right)^{-1}
$$

where $\mathrm{S}$ is a shape factor $(5<\mathrm{S}<30)$ and $\mathrm{K}$ is the bulk modulus in the range $1 \mathrm{GPa}<\mathrm{K}<2.5 \mathrm{GPa}$. 
The first step is to determine horizontal stiffness to ensure a preliminary target period as mentioned above. This can be obtained from:

$$
T_{D}=2 \pi \sqrt{\frac{M}{K_{h}}}
$$

where $T_{D}$ is the target period $\left(T_{D}=2 \mathrm{sec}\right.$, for this study), $M$ is the total mass and $\mathrm{K}_{\mathrm{h}}$ is the horizontal lateral stiffness.

2. Lateral displacement $D_{D}$

$$
D_{D}=\left(\frac{g}{4 \pi}\right) \frac{S_{D i} T_{D}}{B_{D}}
$$

where $\mathrm{S}_{\mathrm{Di}}$ is the design damped spectral acceleration for 1 second period (with $5 \%$ critical damping, in the present study of the $3 \mathrm{D}$ concrete frame), $\mathrm{T}_{\mathrm{D}}$ is the isolated design period and $\mathrm{B}_{\mathrm{D}}$ is a damping coefficient related with the effective damping of the isolation system as shown in Table 4.

\begin{tabular}{|c|c|}
\hline Effective Damping & $\mathrm{B}_{\mathrm{D}}$ \\
\hline$<2 \%$ & 0.8 \\
\hline $5 \%$ & 1.0 \\
\hline $10 \%$ & 1.2 \\
\hline $20 \%$ & 1.5 \\
\hline $30 \%$ & 1.7 \\
\hline $40 \%$ & 1.9 \\
\hline$>50 \%$ & 2.0 \\
\hline
\end{tabular}

Table 4: Damping coefficient $\mathrm{B}_{\mathrm{D}}$

After knowing $\mathrm{D}_{\mathrm{D}}$, the total thickness of the base isolation device is obtained from the following equation:

$$
t=\frac{D_{D}}{\gamma_{\max }}
$$

where $\gamma_{\max }$ is the maximum allowed shear distortion of the isolator $(150 \%$ in this study). The isolator area is obtained directly from $K_{h}$ in equation (1).

3. Finally, the detail of the base isolators (number of rubber layers and thickness) and the buckling stability criteria (Naeim and Kelly [9]) are respectively prepared and ascertained. 
In this study a High-Damping Rubber Bearing (HDRB) base isolation system was used. These elastomeric devices have nonlinear behavior with high stiffness and damping at shear strains less than $20 \%$; at higher shear strains occurs an increase in the energy dissipation as well as an increase in the shear modulus. Generally damping ratios are between $8 \%$ and $20 \%$ of critical damping and the shear modulus is between $0.35 \mathrm{MPa}$ to $1.40 \mathrm{MPa}$.

Based on a HDRB with a shear modulus of $1.2 \mathrm{MPa}$ and a $150 \%$ shear strain, a circular base isolator was selected to be placed bellow all columns (although inner columns can have another isolator type) with the following characteristics: diameter $\varnothing=500 \mathrm{~mm}$ with $150 \mathrm{~mm}$ elastomeric thickness, a horizontal stiffness of $1310 \mathrm{kN} / \mathrm{m}$, a lateral displacement $\mathrm{D}_{\mathrm{D}}=0.18 \mathrm{~m}$ and an effective damping factor of $15 \%$.

The bilinear properties of the base isolator were modeled through the isolator built-in feature in the SAP 2000 software package [5]. A new rigid constraint was created at the bottom of the frame (between the ground and the isolator system) to ensure the same global movement for all isolators.

The fundamental frequencies and mode shapes for the previously analyzed structural configurations, now with base isolation devices, are shown in Figure 8.

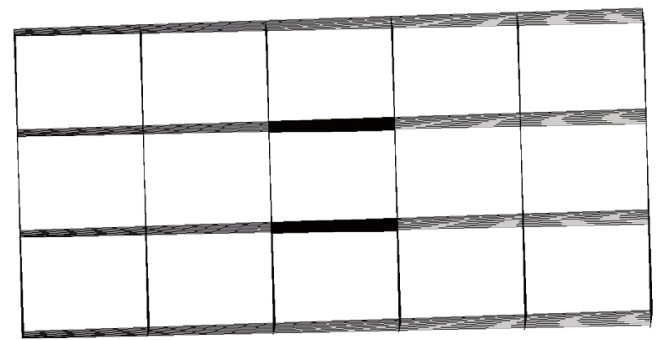

CC1-BI: $\mathrm{f}_{1}=0.34 \mathrm{~Hz}$

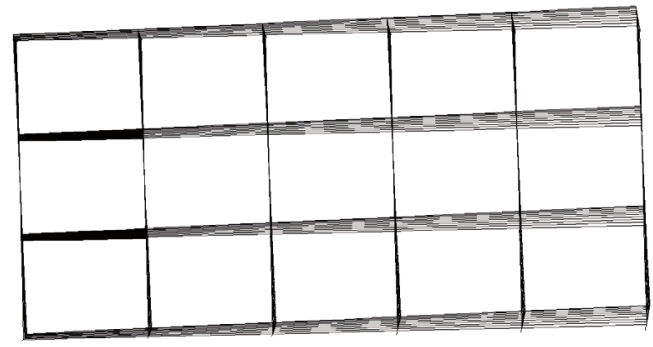

CC3-BI: $\mathrm{f}_{1}=0.31 \mathrm{~Hz}$

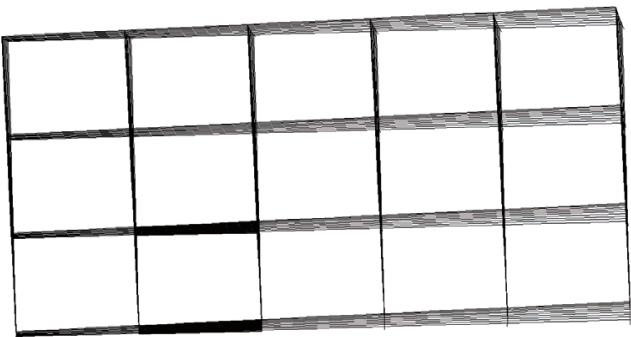

CC5-BI: $\mathrm{f}_{1}=0.32 \mathrm{~Hz}$

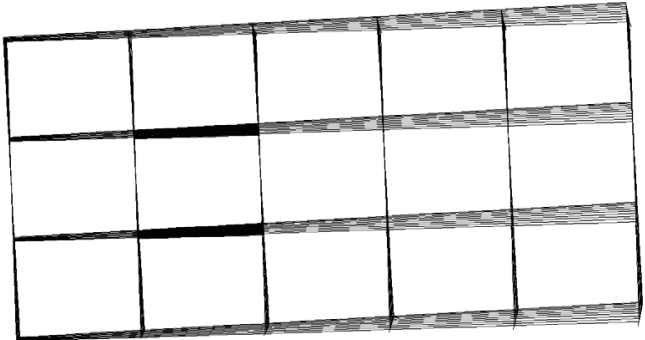

CC2-BI: $\mathrm{f}_{1}=0.32 \mathrm{~Hz}$

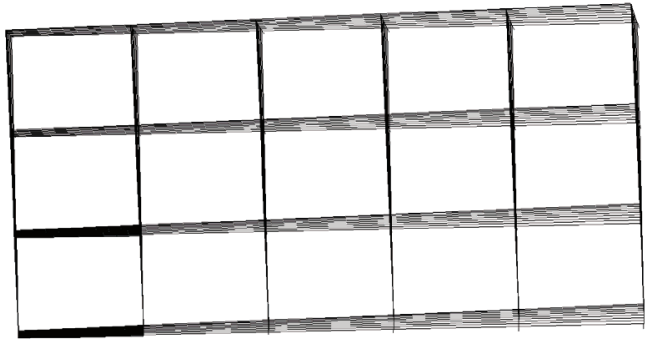

CC4-BI: $\mathrm{f}_{1}=0.31 \mathrm{~Hz}$

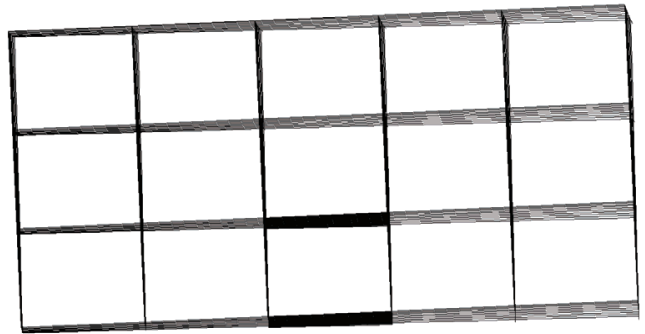

CC6-BI: $\mathrm{f}_{1}=0.33 \mathrm{~Hz}$

Figure 8: Fundamental frequencies and mode shapes for six buildings (with BI) 
It is easily verified that the structural response is strongly conditioned by the introduction of the base isolation devices. In fact, the fundamental frequency practically does not vary for all the six base isolated configurations as well as the associated vibration modes. The only exception is slightly verified in the configuration $\mathrm{CC} 1$ for which the vibration mode has a more significant contribution associated to the translation. This contribution is noticeable in the fundamental mode for which the torsion is not as evident as in the structures without base isolation.

For a more comprehensive analysis of this behavior the Tables 5 and 6 were elaborated in which are presented the results for each one of these configurations. Table 5 contains the frequencies and the modes of vibration of the first six modes. The values of the fundamental frequencies decrease with increasing eccentricity of the concrete core; for $2^{\text {nd }}$ and $3^{\text {rd }}$ modes, the natural frequencies are practically constant for all the parametric variations; the fundamental period is close to $3 \mathrm{sec}$ for all the concrete core locations, a high value close to the maximum target period defined during pre-design of the base isolation supports, but that is inside the normal range of fundamental period values for this type of structures.

\begin{tabular}{|c|c|c|c|c|c|c|c|c|c|c|c|c|}
\hline \multirow{2}{*}{ Mode } & \multicolumn{2}{|c|}{ CC1-BI } & \multicolumn{2}{c|}{ CC2-BI } & \multicolumn{2}{c|}{ CC3-BI } & \multicolumn{2}{c|}{ CC4-BI } & \multicolumn{2}{c|}{ CC5-BI } & \multicolumn{2}{c|}{ CC6-BI } \\
\cline { 2 - 12 } & $\begin{array}{c}\text { Freq } \\
\text { (Hz) }\end{array}$ & mode & $\begin{array}{c}\text { Freq } \\
\text { (Hz) }\end{array}$ & mode & $\begin{array}{c}\text { Freq } \\
\text { (Hz) }\end{array}$ & mode & $\begin{array}{c}\text { Freq } \\
\text { (Hz) }\end{array}$ & mode & $\begin{array}{c}\text { Freq } \\
(\mathbf{H z})\end{array}$ & mode & $\begin{array}{c}\text { Freq } \\
(\mathbf{H z})\end{array}$ & mode \\
\hline 1 & 0.34 & $\mathrm{Ty}$ & 0.32 & $\mathrm{Rz}$ & 0.31 & $\mathrm{Rz}$ & 0.31 & $\mathrm{Rz}$ & 0.32 & $\mathrm{Rz}$ & 0.33 & $\mathrm{Rz}$ \\
\hline 2 & 0.35 & $\mathrm{Tx}$ & 0.34 & $\mathrm{Tx}$ & 0.34 & $\mathrm{Tx}$ & 0.34 & $\mathrm{Txy}$ & 0.35 & $\mathrm{Txy}$ & 0.35 & $\mathrm{Txy}$ \\
\hline 3 & 0.38 & $\mathrm{Rz}$ & 0.38 & $\mathrm{Rz}$ & 0.38 & $\mathrm{Rz}$ & 0.38 & $\mathrm{Rz}$ & 0.38 & $\mathrm{Rz}$ & 0.38 & $\mathrm{Rz}$ \\
\hline 4 & 1.40 & $\mathrm{Rz}$ & 1.21 & $\mathrm{Rz}$ & 1.16 & $\mathrm{Rz}$ & 1.14 & $\mathrm{Rz}$ & 1.22 & $\mathrm{Rz}$ & 1.31 & $\mathrm{Rz}$ \\
\hline 5 & 1.62 & $\mathrm{Tx}$ & 1.58 & $\mathrm{Tx}$ & 1.52 & $\mathrm{Tx}$ & 1.50 & $\mathrm{Txy}$ & 1.53 & $\mathrm{Txy}$ & 1.48 & $\mathrm{Txy}$ \\
\hline 6 & 1.78 & $\mathrm{Rz}$ & 1.92 & $\mathrm{Rz}$ & 2.24 & $\mathrm{Rz}$ & 2.17 & $\mathrm{Rz}$ & 1.99 & $\mathrm{Rz}$ & 1.83 & $\mathrm{Rz}$ \\
\hline
\end{tabular}

Tx: Translation x-x; Ty: Translation y-y; Txy: Translation x-x and y-y; Rz: Rotation z-z (or torsion)

Table 5: Natural frequencies and mode shapes for the base isolated (BI) structures

Table 6 contains the first 12 modal participation mass ratios (\%) for the six base isolated structural configurations of the concrete core.

\begin{tabular}{|c|c|c|c|c|c|c|c|c|c|c|c|c|c|c|c|c|c|c|}
\hline \multirow{2}{*}{ M } & \multicolumn{3}{|c|}{ CC1 (\%) } & \multicolumn{3}{|c|}{ CC2 (\%) } & \multicolumn{3}{|c|}{ CC3 $(\%)$} & \multicolumn{3}{|c|}{ CC4 (\%) } & \multicolumn{3}{|c|}{$\operatorname{CC5}(\%)$} & \multicolumn{3}{|c|}{ CC6 (\%) } \\
\hline & $\mathbf{x x}$ & yy & $\theta \mathrm{z}$ & $\mathbf{x x}$ & yy & $\theta \mathrm{z}$ & $\mathbf{x x}$ & yy & $\theta \mathrm{z}$ & $\mathbf{x x}$ & yy & $\theta \mathrm{z}$ & $\mathbf{x x}$ & yy & $\theta \mathrm{z}$ & $\mathbf{x x}$ & yy & $\theta \mathrm{z}$ \\
\hline 1 & 0 & 96 & $\overline{72}$ & 0 & 90 & 77 & 0 & 92 & 72 & 6 & 88 & 83 & 8 & 84 & 88 & 12 & 81 & 89 \\
\hline 2 & 99 & 0 & 14 & 99 & 0 & 14 & 99 & 0 & 14 & 93 & 6 & 3 & 89 & 10 & 2 & 83 & 15 & 1 \\
\hline 3 & 0 & 0 & 14 & 0 & 9 & 8 & 0 & 6 & 12 & 1 & 5 & 12 & 2 & 5 & 8 & 5 & 3 & 9 \\
\hline 4 & 0 & 0 & 0 & 0 & 1 & 1 & 0 & 1 & 1 & 0 & 1 & 2 & 0 & 1 & 2 & 0 & 1 & 1 \\
\hline 5 & 0 & 0 & 0 & 1 & 0 & 0 & 1 & 0 & 0 & 0 & 0 & 0 & 1 & 0 & 0 & 0 & 0 & 0 \\
\hline 6 & 1 & 0 & 0 & 0 & 0 & 0 & 0 & 0 & 0 & 0 & 0 & 0 & 0 & 0 & 0 & 0 & 0 & 0 \\
\hline 7 & 0 & 0 & 0 & 0 & 0 & 0 & 0 & 0 & 0 & 0 & 0 & 0 & 0 & 0 & 0 & 0 & 0 & 0 \\
\hline 8 & 0 & 0 & 0 & 0 & 0 & 0 & 0 & 0 & 0 & 0 & 0 & 0 & 0 & 0 & 0 & 0 & 0 & 0 \\
\hline 9 & 0 & 0 & 0 & 0 & 0 & 0 & 0 & 0 & 0 & 0 & 0 & 0 & 0 & 0 & 0 & 0 & 0 & 0 \\
\hline 10 & 0 & 0 & 0 & 0 & 0 & 0 & 0 & 0 & 0 & 0 & 0 & 0 & 0 & 0 & 0 & 0 & 0 & 0 \\
\hline 11 & 0 & 0 & 0 & 0 & 0 & 0 & 0 & 0 & 0 & 0 & 0 & 0 & 0 & 0 & 0 & 0 & 0 & 0 \\
\hline 12 & 0 & 0 & 0 & 0 & 0 & 0 & 0 & 0 & 0 & 0 & 0 & 0 & 0 & 0 & 0 & 0 & 0 & 1 \\
\hline
\end{tabular}

\begin{tabular}{|l|l|l|l|l|l|l|l|l|l|l|l|l|l|l|l|l|l|l|}
$\Sigma$ & 100 & 96 & 100 & 100 & 100 & 100 & 100 & 99 & 99 & 100 & 100 & 100 & 100 & 100 & 100 & 100 & 100 & 100 \\
\hline
\end{tabular} $\mathrm{xx}$ : translation $\mathrm{x}-\mathrm{x} ; \quad \mathrm{yy}$ : translation $\mathrm{y}-\mathrm{y} ; \quad \theta \mathrm{z}$ : rotation $\mathrm{z}-\mathrm{z}$

Table 6: Modal participation mass ratios (\%) for the six base isolated structures 
From Table 6 it is observed that all the structures have a similar behavior; the modal participation mass ratios associated with translation increases (with respect to the non-isolated structures), and such effect is concentrated in the first two modes. Also, beyond $4^{\text {th }}$ mode, the contribution of the remaining modes is un-significant since practically a value of $100 \%$ is obtained for the cumulative modal participation mass ratios with the first three modes.

The torsion effect is shown to be more significant in the $1^{\text {st }}$ mode and less significant in the remaining modes. Therefore the base isolation devices lead to a more uniform dynamic behavior of the structural configurations analyzed, for distinct concrete core locations, therefore indicating that the concrete core location is not important when base isolation devices are used.

A simplified spectral seismic analysis of the isolated buildings (using NA of EC8, as was done for the non-isolated buildings) was carried out for the most unfavorable seismic actions acting in y-y direction. The relative horizontal floor displacements, at reference column P6 (labelled in Figure 1) and at the concrete core, are represented in Figures 9 and 10 respectively for each $\mathrm{x}-\mathrm{x}$ and $\mathrm{y}-\mathrm{y}$ directions.

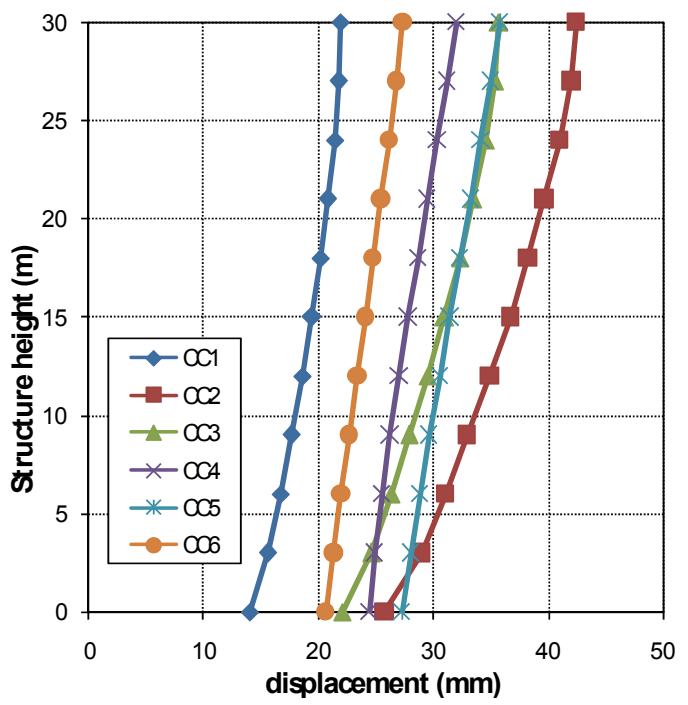

(a)

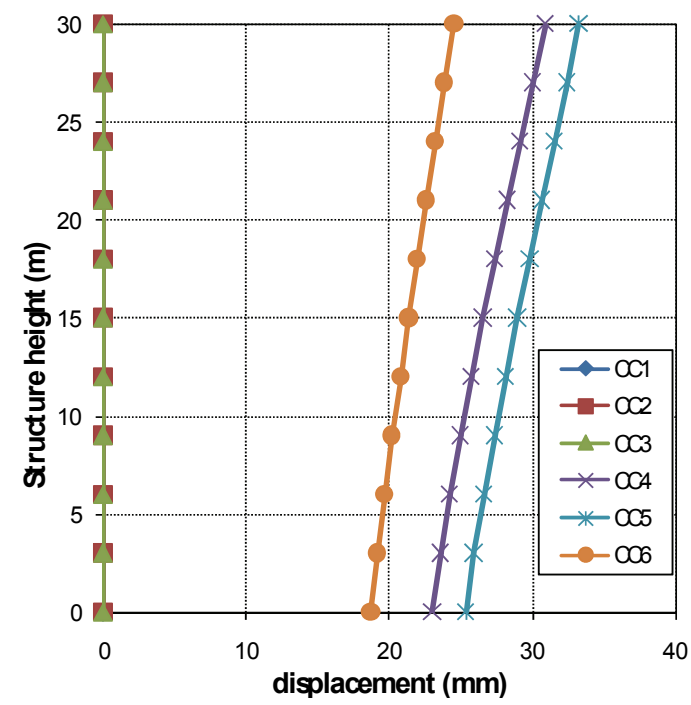

(b)

Figure 9: Horizontal x-x displacements (with BI): a) P6 column; b) concrete core

In relation to the horizontal displacements along $x-x$ axis (Figure 9) it is verified that the variation along the height of the buildings is considerably less significant (than the one that occurred in Figure 5, for the non-isolated buildings): the interstorey drift decreases significantly relatively to the configurations with rigid base connections. Similar considerations can be made for the horizontal displacements in the $y$-y direction (Figure 10) with a more uniform trend than the one that occurred for the non-isolated buildings (Figure 6).

In both cases the decrease of the torsion effect again indicates a more uniform dynamic behavior of the distinct structural configurations of the concrete core and consequently an improved seismic response and performance of the structures equipped with base isolation (BI) devices. 
Once again it can be concluded that the introduction of the base isolation devices, makes less important the location of the resisting concrete cores as a significant source of stiffness asymmetries and therefore of quite distinct torsion behavior.

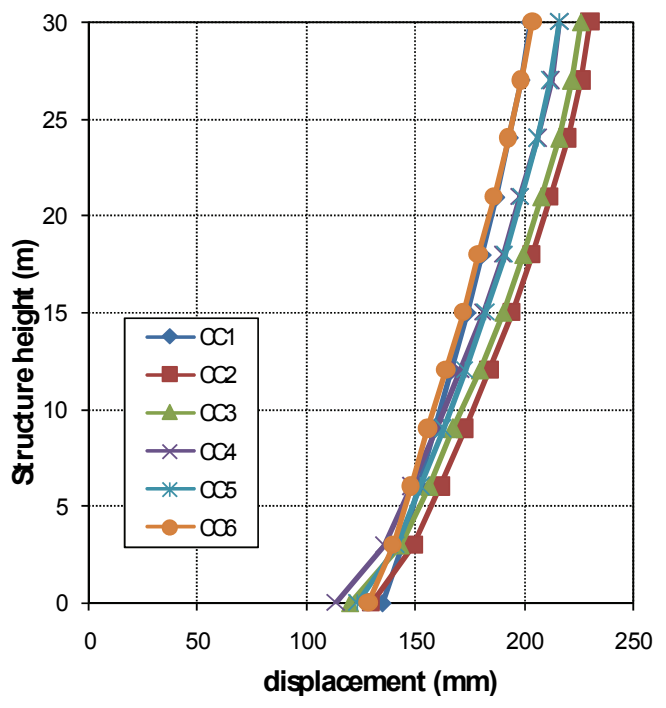

(a)

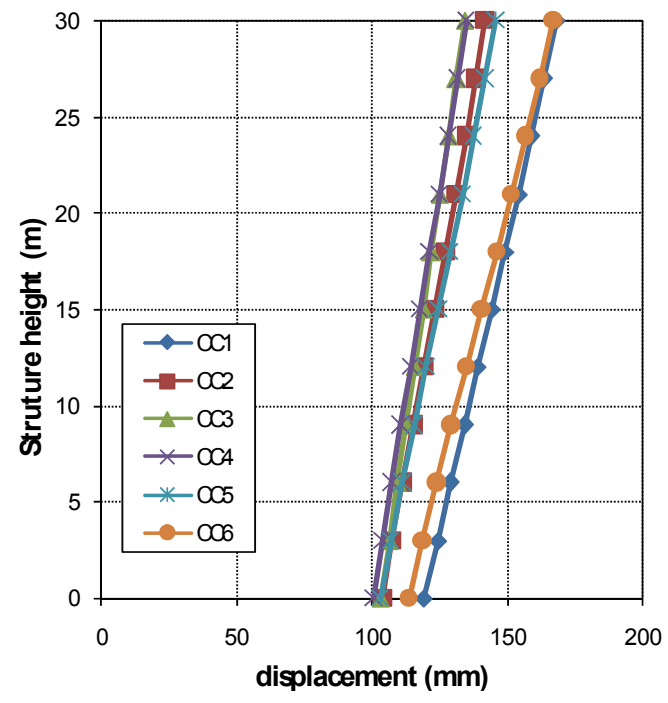

(b)

Figure 10: Horizontal y-y displacements (with BI): a) P6 column; b) concrete core

\subsection{Relative importance of the basal shear}

The bar diagrams in Figures 11 and 12 represent the ratios between the basal shear and the structural weight, for the distinct structural configurations associated with the concrete core location, respectively for non-isolated and base-isolated structures.

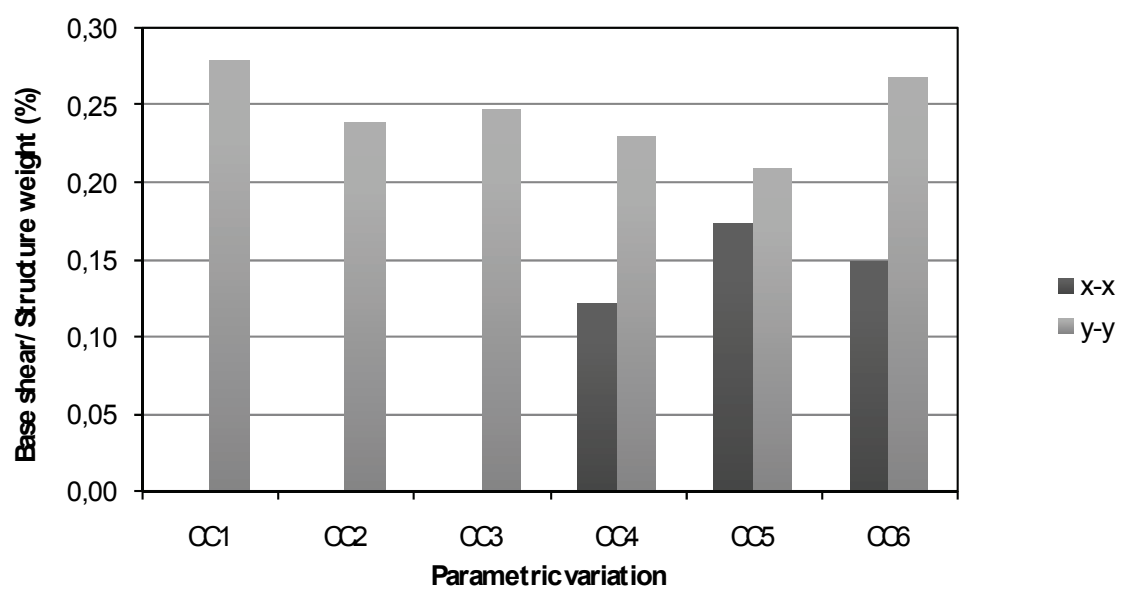

Figure 11: Ratio basal shear/structural weight for the non-isolated structures (\% of structure weight) 


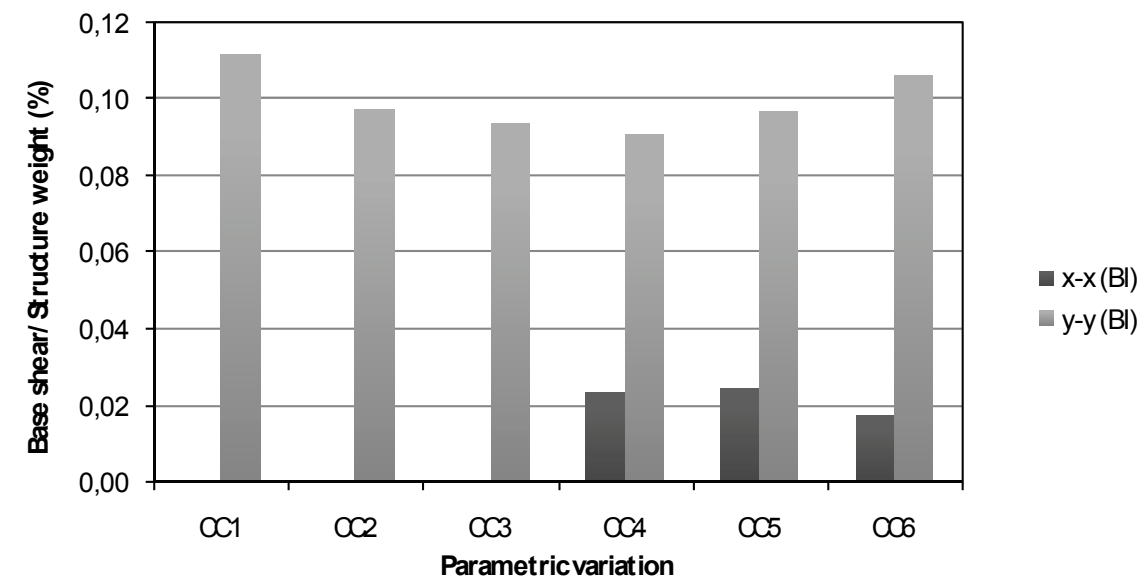

Figure 12: Ratio basal shear/structural weight for the base-isolated structures (\% of structure weight)

In Figure 11, related to the basal shear for the non-isolated structures, a better behavior occurs for core configurations closer to the center of mass of the structure; when the core is not placed along the central symmetry axis, a new basal shear component also occurs along $\mathrm{x}-\mathrm{x}$ direction (of the order of $15 \%$ of the structural weight), therefore showing the effect of torsion for such configurations.

In Figure 12, related to the basal shear for the base-isolated structures, it is observed the significant reduction of the seismic forces: now with BI, around 10\% of the structural weight; as compared with the $25 \%$ of structural weight, without BI. Also the basal shear along $\mathrm{x}-\mathrm{x}$ direction (due to the torsion effect) is now reduced to $2 \%$ of the structural weight, emphasizing that base isolation significantly improves the global seismic behavior of structures.

It is important that a BI device should have a considerable capacity of energy absorption, which is accounted for in the selection design phase by using a dissipation model based on the linear viscous damping behavior of the base isolation devices. Therefore one of the final difficulties is related with the selection of the real modal damping factors (Alhan and Gavin [10]) (Osinski, [11]) and ascertain the consequences of such values in the analyses, as addressed by the second author in a recent accompanying paper (Figueiredo and Barros [12]).

\subsection{Dynamic and seismic response of an asymmetric structure}

To confirm that the obtained results are not an isolated case occurrence, a new structural configuration was analyzed without and with base isolation devices but with an asymmetrical plan arrangement. Since the worst concrete core configuration is associated with the CC4 structural configuration, an in-plan asymmetrical structure (stiffness asymmetry CC4A core) was created (eliminating appropriately contributions of frames in both plan and elevation) as shown in Figure 13.

Figure 14 indicates the fundamental natural frequencies of the stiffness asymmetric structure considered herein, without and with BI devices, and shows the corresponding mode shapes (using the same scale factor). 


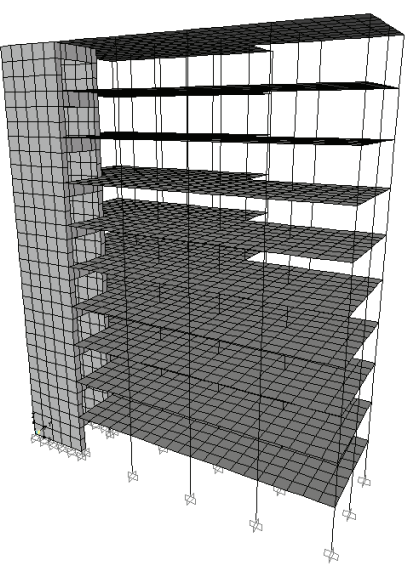

(a)

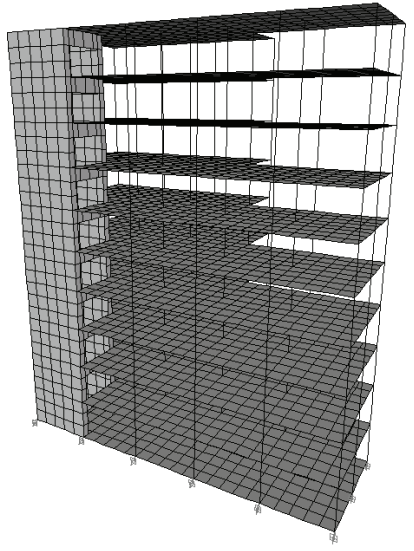

(b)

Figure 13: Perspective view of the in-plan asymmetric structure CC4A a) without $\mathrm{BI}$; b) with $\mathrm{BI}$

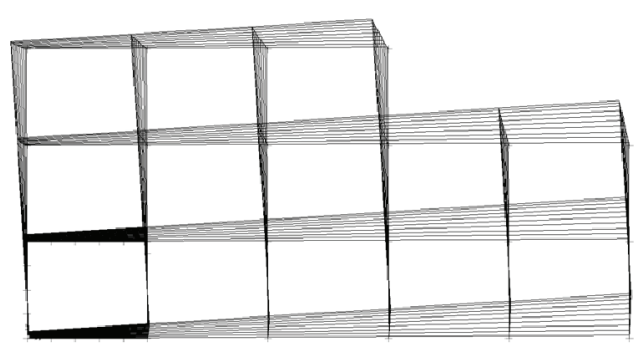

CC4A: $\mathrm{f}_{1}=0.63 \mathrm{~Hz}$

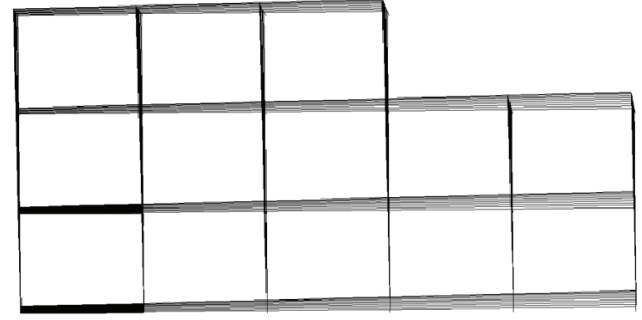

CC4A-BI: $f_{1}=0.33 \mathrm{~Hz}$

Figure 14: Fundamental natural frequencies and mode shapes - Asymmetric structure (CC4A) without and with BI devices

In Figure 14 it is quite visible the attenuation of the torsion effect caused by the use of the base isolation devices. The fundamental natural frequency of the structure with BI and in-plan geometric or stiffness asymmetry does not change significantly, when compared with the value associated with in-plan symmetric structure with BI (Figure 8). However, the largest consequence of the introduction of the BI is the decrease of the relative displacements (inter-storey drifts) between adjacent floors.

In Table 7 are given the modal participation mass ratios (in percentage) for the asymmetrical structure (CC4A) without and with BI devices (as well as the corresponding natural frequencies and mode shapes information).

The asymmetric structural configuration (CC4A) without BI devices has structural behavior characteristics controlled by torsion effect, similar to the structural configuration $\mathrm{CC} 4$ without $\mathrm{BI}$ devices (Table 2). The asymmetric structural configuration (CC4A) with BI devices has a structural behavior very similar to the one already obtained for the symmetric in-plan structure with same location of the concrete core (CC4) with BI devices (Table 5). 


\begin{tabular}{|c|c|c|c|c|c|c|c|c|c|c|c|}
\hline \multirow{2}{*}{ Mode } & \multicolumn{1}{|c|}{ CC4A } & \multicolumn{1}{c|}{ CC4A-BI } \\
\cline { 2 - 13 } & Freq (Hz) & mode & $\mathbf{x x}$ & $\mathbf{y y}$ & $\boldsymbol{\theta z}$ & Freq (Hz) & $\mathbf{m o d e}$ & $\mathbf{x x}$ & $\mathbf{y y}$ & $\boldsymbol{\theta z}$ \\
\hline 1 & 0.63 & $\mathrm{Rz}$ & 4 & 54 & 73 & 0.32 & $\mathrm{Rz}$ & 4 & 92 & 74 \\
\hline 2 & 1.06 & $\mathrm{Tx}$ & 61 & 5 & 2 & 0.34 & $\mathrm{Tx}$ & 95 & 5 & 3 \\
\hline 3 & 1.53 & $\mathrm{Rz}$ & 1 & 6 & 5 & 0.38 & $\mathrm{Rz}$ & 0 & 2 & 21 \\
\hline 4 & 1.85 & $\mathrm{Rz}$ & 1 & 16 & 8 & 1.21 & $\mathrm{Rz}$ & 0 & 2 & 2 \\
\hline 5 & 3.13 & $\mathrm{Rz}$ & 0 & 3 & 5 & 1.58 & $\mathrm{Tx}$ & 1 & 0 & 0 \\
\hline 6 & 4.36 & $\mathrm{Txy}$ & 18 & 3 & 0 & 1.92 & $\mathrm{Rz}$ & 0 & 0 & 0 \\
\hline
\end{tabular}

Tx: Translation x-x; Ty: Translation y-y; Txy: Translation $x-x$ and y-y; Rz: Rotation z-z (or torsion)

Table 7: Natural frequencies, mode shapes and modal participation mass ratios (\%) for the asymmetrical structure (CC4A) without and with BI devices

The in-plan geometric or stiffness asymmetry does not cause significant change in the natural frequencies, as compared with the geometric or almost stiffness symmetric case. The modal participation mass ratios of both symmetrical (CC4) and asymmetrical (CC4A) building configurations only change significantly for the $3^{\text {rd }}$ mode, for which the mass associated with torsion effects increases.

A simplified spectral seismic analysis of the stiffness asymmetric building, without and with BI devices, was carried out for the most unfavorable seismic actions acting in $y-y$ direction. The floor displacements, at reference column P6 and at the concrete core, are represented in Figures 15 and 16 for each $\mathrm{x}-\mathrm{x}$ and $\mathrm{y}-\mathrm{y}$ directions, for $4 \mathrm{CC} 4$ configurations: without $\mathrm{BI}$ and without asymmetry; without $\mathrm{BI}$ but with asymmetry; with BI but without asymmetry; with BI and with asymmetry.

The seismic behavior is not significantly changed for the asymmetric configurations (without or with BI), specially in the $y-y$ direction for which the changes are minor for the core displacements and practically null for the displacements along the reference column P6. The use of BI devices causes a decrease of the "drift" for the 2 structural configurations being compared. The global behavior is very similar in both cases, as represented by curves either almost coincident or with almost similar gradients or evolutions.

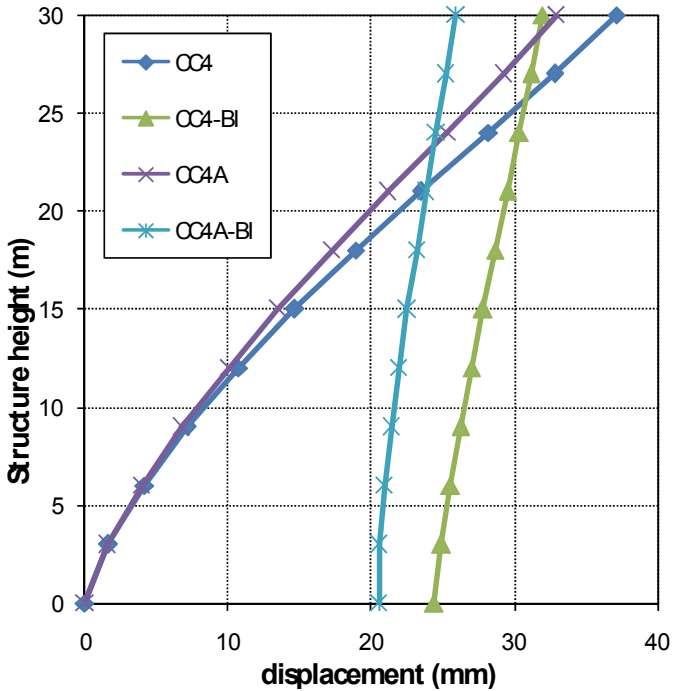

(a)

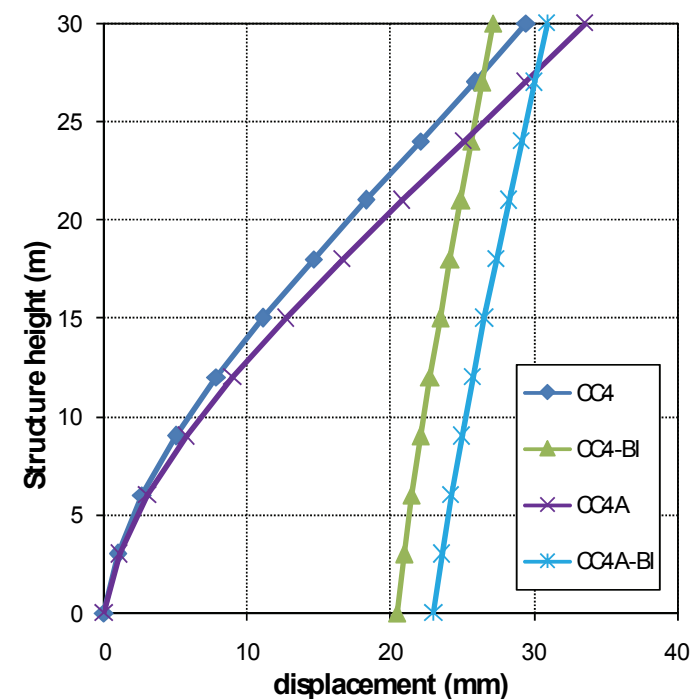

(b)

Figure 15: Horizontal x-x displacement: a) P6 column; b) concrete core 


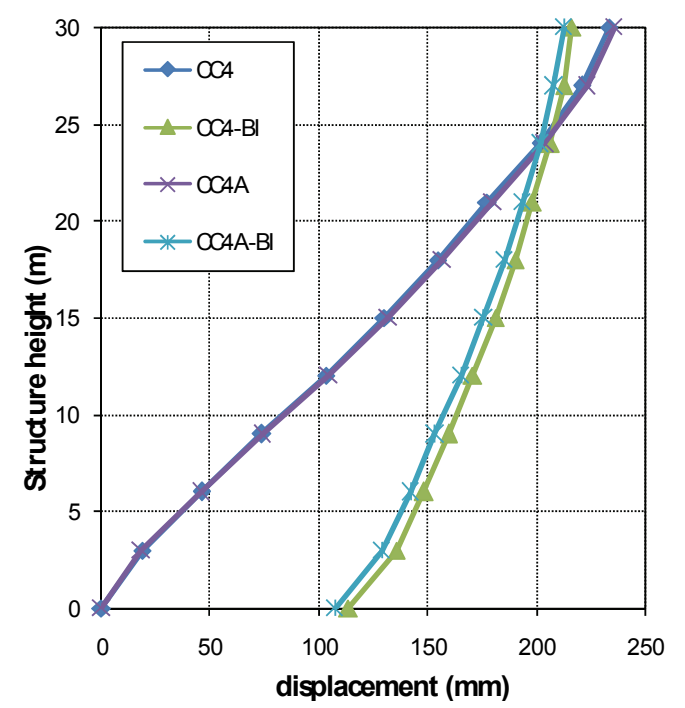

(a)

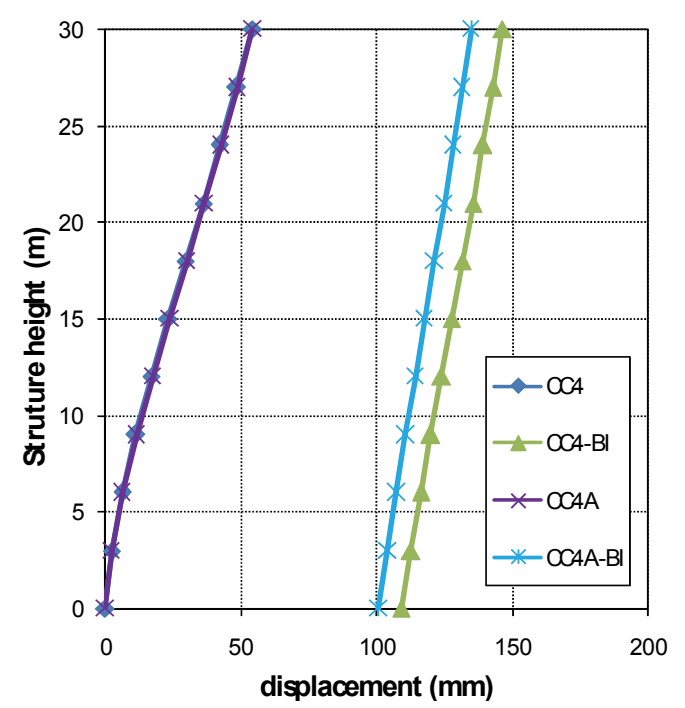

(b)

Figure 16: Horizontal y-y displacement: a) P6 column; b) concrete core

The horizontal $\mathrm{x}-\mathrm{x}$ displacements, of reference column $\mathrm{P} 6$ and core, show a more noticeable shift for the in-plan geometric or asymmetric case. Nevertheless, in view of the small relative differences (maximum of 15\%) between the displacement values associated with the configurations with BI devices, it may be concluded that at least for the analyzed structures the BI constitute an efficient device to control torsion effects in asymmetric structures.

\section{Conclusions}

This article presented a study about the importance of a resistant concrete core location in a reinforced concrete 3D frame, asymmetric in plan and in elevation, in order to emphasize the torsion effect in the seismic behavior of the structure. Since torsion is quite detrimental for the structural seismic capacity, in view of the seismic forces it generates among the seismic-resisting members in the structure, its negative effect was attenuated through the inclusion of HDRB base isolation devices.

It was verified that base isolation significantly improves the structural behavior, and that the torsion effect associated with the resistant concrete core location is quite reduced when using $\mathrm{BI}$, becoming practically invariant for the parametric variations studied. Even for a modeled structure with asymmetries in plan and in elevation (stiffness asymmetries) it was verified that, for the analyzed cases, the asymmetry did not create a significant loss of performance of the BI devices. Also the seismic forces, as measured by the basal shears, are drastically decreased by the implementation of such devices designed according to available methodologies.

Obviously that the use of these BI devices requires a cost analysis, but for architectural projects similar to the structures analyzed herein the use of such devices can be the adequate technical-economic solution, as compared with the increase of resisting sections of members or the introduction of visco-elastic braces in a variety of possible configurations. 


\section{Acknowledgements}

This paper reports research developed on Base Isolation under the R\&D Eurocores Project COVICOCEPAD within the S3T Program, approved independently by European Science Foundation (ESF, Strasbourg), through financial support provided by "FCT - Fundação para a Ciência e a Tecnologia" (Lisbon, Portugal).

\section{References}

[1] Barros, R.C. and Cesar, M.B., "A Parametric Study on the Seismic Behaviour of an Asymmetric Three-Dimensional Steel Frame with Base Isolation Devices", CONVIB Network Final Meeting, Santorini - Greece (June $30^{\text {th }}$ July $1^{\text {st }}$ 2005), CD-Ed.: L Faravelli and F Casciatti, Univ of Pavia, Italy, 2006.

[2] Barros, R.C. and Cesar, M.B., "Seismic Behaviour of an Asymmetric ThreeDimensional Steel Frame with Base Isolation Devices", in Proceedings of The Eighth International Conference on Computational Structures Technology; B.H.V. Topping, G. Montero and R. Montenegro, (Editors); Civil-Comp Press, Stirlingshire, United Kingdom, Paper 252, 2006.

[3] Cesar, M.B. and Barros, R.C., "Parametric Study of the Non-Linear Geometric Behaviour and Carrying Capacity of 3D Asymmetric Steel Frames", in Proceedings of the Tenth International Conference on Civil, Structural and Environmental Engineering Computing; B.H.V. Topping, (Editor); CivilComp Press, Stirlingshire, United Kingdom, Paper 155, 2005.

[4] CEN-EC2, "Eurocode 2: Design of Concrete Structures", Part 1-1: General Rules and Rules for Buildings, EN 1992-1-1, European Committee for Standardization, Brussels, 2004.

[5] SAP 2000, "SAP 2000 Software Verification", Computers and Structures Inc., Berkeley, California, USA, 2003.

[6] SAP 2000, "SAP 2000 Analysis Reference Vol. 1 \& 2", Computers and Structures Inc., Berkeley, California, 2005.

[7] CEN-EC8, "Eurocode 8: Design of Structures for Earthquake Resistance", Part 1: General Rules, Seismic Actions and Rules for Buildings, EN 1998-1, European Committee for Standardization, Brussels, 2004.

[8] Skinner, R.I., Robinson, W.H., and McVerry, G.H., "An Introduction to Seismic Isolation", John Wiley \& Sons Inc., 1993.

[9] Naeim, F. and Kelly, J.M., "Design of Seismic Isolated Structures: from Theory to Practice", John Wiley \& Sons Inc., 1999.

[10] Alhan, C. and Gavin, H., "Parametric Analysis of Passive Damping in Base Isolation", 16th ASCE Engineering Mechanics Conference (July 16-18, 2003), University of Washington, Seattle, USA, 2003.

[11] Osinski, Z. (editor), Damping of Vibrations, A.A. Balkema Publishers, Rotterdam, Netherlands, 1998.

[12] Figueiredo, E. and Barros, R.C., "A Influência do Amortecimento em Isolamento Sísmico", Sísmica 2007 - $7^{\text {th }}$ National Meeting on Seismology and Earthquake Engineering, Universidade do Porto, FEUP, Portugal (in-press). 